\title{
BAOMS launches enhanced website
}

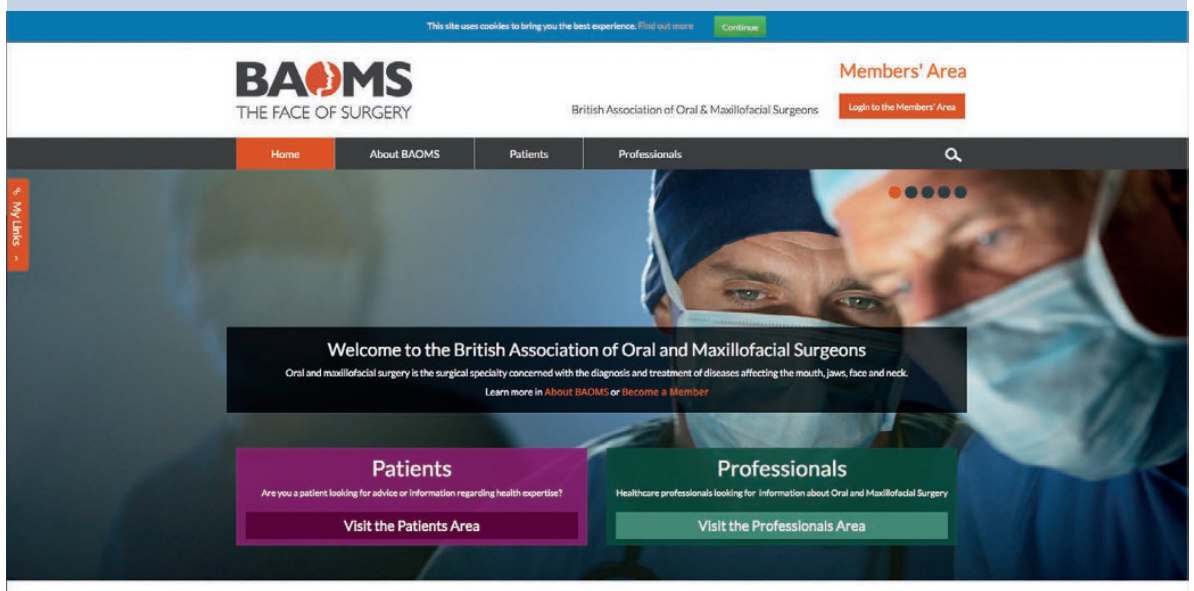

ELSEVIER “" $\because$ ScienceDirect (DH) Department

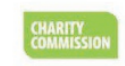

JustGiving
The British Association of Oral and Maxillofacial Surgery (BAOMS) has launched a new website with enhanced public and patient information and resources for health professionals.

Healthcare professionals can access the latest OMFS news including courses, events, research and audit. An education and training section contains e-learning resources such as ProjecTrain. The Members' area has a direct one-click access to the British Journal of Oral and
Maxillofacial Surgery (BJOMS) as well as discussion forums for sub-specialty interest groups (SSIGs) such as oncology.

BAOMS Honorary Web Editor Andrew Baker said: 'We need a platform to promote ourselves as well as a way of rapidly cascading views to help us develop and support best practice. I am sure the new website is a major step forward in achieving this aim?

The new BAOMS website can be found at: www.baoms.org.uk.

\section{BDA AGMs}

West Lancs, West Cheshire,

North Wales

The West Lancs, West Cheshire, North Wales Branch AGM will be held on 15 February at Wirral Postgraduate Medical Centre, Clatterbridge Hospital, CH63 4JY at 18:15, before the educational meeting.

Papers for the meeting can be downloaded from the events page of the BDA website or requested from the Branch Secretary. If you wish to submit apologies please contact Linda Dunlop on ldunlop76@aol.com.

\section{East of Scotland}

The East of Scotland Branch AGM will be held on 29 March 2017 at the Hepburn Suite of The Royal Scots Club, 30 Abercromby Place, Edinburgh, EH3 6QE. The meeting will be held before the educational meeting and registration is from 18:45.

To confirm attendance or submit apologies please contact Suja Kurien at bdaeastofscotland@gmail.com.

\section{Honours, awards, appointments}

\section{New Year Honours \\ $M B E$}

Professor Elizabeth Jane Kay, Associate Dean for Equality and Inclusion and Foundation Dean at the Plymouth University Peninsula School of Dentistry, has been awarded a Member of the Order of the British Empire (MBE) for services to dental education in the New Year Honours. Professor Kay is a member of the BDA's Dental Public Health Committee, a cross-representative on the BDA's Health and Science Committee and a member of the BDJ Editorial Board.

Miss Sarah Marianne Murray, a principal dental hygienist/therapist and Senior Lecturer, Head of Centre and Programme Lead, Institute of Dentistry, Queen Mary University of London, has also been awarded an MBE, for services to oral health.

\section{BEM}

Peter Heasman, Professor of Periodontology at Newcastle Dental School was awarded a Medal of the Order of the British Empire (BEM), for his services providing ethical review and support to researchers.

\section{BDA PEC}

The following people will be joining the BDA's Principal Executive Committee for the 2017-19 triennium: Anthony Kilcoyne (UK-wide); Alison Lockyer (East Midlands and Central); Russ Ladwa (Greater London); Victor Chan (South East); and Derek Harper (Scotland). These members join the board as of this month and join ten sitting members.

\section{AO International President}

Dr Mervyn Druian has become the International President of the Alpha Omega Society (AO) for 2017. The AO is the oldest international medical society and promotes social justice and Judaic values through philanthropic activities and dental education.

\section{Lords health minister}

In a mini reshuffle just before Christmas, Lord O'Shaughnessy replaced Lord Prior as the health minister in the Lords. Lord O'Shaughnessy is a former lobbyist and adviser to David Cameron. 